\title{
ANALISIS EVOLUSI EKOSISTEM PERANGKAT LUNAK OPEN SOURCE : TINJAUAN PUSTAKA SISTEMATIS
}

\section{Analysis Of Evolution Of Open Source Software Ecosystems : Systematic Literature Review}

\author{
Dwi Shinta Angreni ${ }^{1}$ dan Yunita Prastyaningsih ${ }^{2}$ \\ ${ }^{1}$ Jurusan Teknologi Informasi, Fakultas Teknik, Universitas Tadulako \\ ${ }^{2}$ Program Studi Teknik Informatika, Politeknik Negeri Tanah Laut \\ e-mail: ${ }^{1}$ ds.angreni@untad.ac.id, ${ }^{2}$ nitaprastya@gmail.com
}

\begin{abstract}
The development of an Open Source Software (OSS) can influence the development of other Open Source Systems. The relationship between OSS is often called an ecosystem, there are several aspects to the OSS ecosystem that can affect ecosystem evolution in the software. This study reports a systematic literature review on the influence of several aspects of the OSS ecosystem on the evolution of OSS. The Sistematic Literature Review method based on Kitchenham was used to analyze 1099 articles published in leading journals and conferences. The Results showed that Social aspects have a significant impact on ecosystem evolution, where communication between communities in an OSS ecosystem influences aspects of contributions and dependencies that encourage an ecosystem to develop and evolve.
\end{abstract}

Keywords- Software Ecosystem, OSS Ecosystem, Evolution of OSS Ecosystem

\section{Pendahuluan}

Sistem perangkat lunak perlu berkembang dan beradaptasi. Oleh karenanya setiap software harus terus berevolusi untuk menjaga eksistensinya [1]. Namun dalam mengembangkan dan memperbaharui sebuah sistem perangkat lunak bukan hal yang mudah terlebih lagi jika sistem yang digunakan merupakan sistem yang lama dan masih dalam perkembangan. Salah satu software yang perkembangannya sangat pesat saat ini adalah open source software (OSS)[2].

Perkembangan suatu OSS dapat mempengaruhi perkembangan OSS lainnya. Hubungan antar software OSS ini sering disebut ekosistem. Istilah ekosistem sering muncul dalam media saat ini dimana kesuksesan dalam ekosistem berarti sukses pada bisnis[3]. Namun untuk sukses, pebisnis software tidak hanya menyediakan produk dan layanan tapi juga dapat membangun sebuah ekosistem yang baik [4].

Studi sejarah dan empiris OSS ekosistem masih relatif baru tapi merupakan salah satu penelitian yang perkembangannya sangat pesat. Karakteristik penting pada ekosistem ini adalah dibuat dari sekumpulan projek berbagi di sebuah komunitas pengguna dan kontributor [2]. Saat ini sudah banyak penelitian yang menganalisa ekosistem OSS, pada paper ini kami akan membahas beberapa aspek pada ekosistem OSS yang dapat mempengaruhi evolusi ekosistem pada perangkat lunak tersebut.

Mengetahui aspek yang dapat mempengaruhi sebuah ekosistem sangat penting bagi perusahaan 
atau pengembang. Hal ini penting agar mereka mengetahui langkah-langkah yang harus dilakukan dalam mensukseskan ekosistem yang mereka bangun. Terdapat banyak aspek yang dapat mempengaruhi sebuah evolusi ekosistem, dalam paper ini akan dibahas tiga aspek ekosistem OSS yaitu aspek sosial, aspek kontribusi, dan aspek dependency. Tujuan dari paper ini adalah untuk melihat dan menyajikan pengaruh aspek-aspek ekosistem OSS pada evolusi OSS.

\section{Metode Penelitian}

Dalam hal untuk mencapai tujuan dari penelitian ini kami menggunakan metode berdasarkan pendekatan Kitchenham dan Charters [5] yaitu menggunakan metode Systematic Literature Review. Systematic Literature Review adalah cara untuk mengidentifikasi, mengevaluasi dan menafsirkan semua penelitian yang tersedia dan yang relevan dengan pertanyaan tertentu pada suatu penelitian, atau bidang topik, atau fenomena yang menarik. Tahapan-tahapan dalam Systematic Literature Review adalah menentukan research question, proses pencarian, study selection, quality assesment, dan proses ekstraksi data.

\subsection{Research Question}

Berikut research question yang kami tentukan dengan tujuan melihat pengaruh ketiga aspek tersebut terhadap ekositem OSS:

RQ1. Aspek-aspek apa saja yang ada pada ekosistem OSS ?

Tujuan dari pertanyaan ini untuk mengetahui aspek-aspek apa saja yang mempengaruhi ekosistem OSS. Aspek-aspek ini berupa hal-hal yang dapat mempengaruhi sebagian atau seluruh ekosistem OSS.

RQ2. Bagaimana pengaruh aspek-aspek tersebut terhadap evolusi ekosistem OSS ?

Tujuan dari pertanyaan ini untuk mengetahui bagaimana pengaruh aspek-aspek tersebut terhadap evolusi ekosistem OSS. Dengan mengetahui pengaruh-pengaruhnya diharapkan para pemain ekosistem OSS dapat mengantisipasi peengaruh tersebut agar dapat menambah kesempatan mereka untuk mensukseskan ekosistem OSS mereka masing-masing.

\subsection{Posisi Penempatan}

Dalam proses pencarian ini agar mendapatkan sumber dengan kualitas yang baik dan ter baru kami mencari sumber literatur dengan mengakses beberapa digital library. Berikut dua sumber digital library yang kami pilih :

1. https://www.sciencedirect.com/

2. https://ieeexplore.ieee.org/

Kedua sumber tersebut kami pilih berdasarkan kemudahan aksesnya dan juga karena kualitas literatur yang diberikan sangat baik dan diakui secara internasional. Memiliki koleksi literatur yang banyak dan juga lengkap dalam bidang teknik dan teknologi. Selain itu fitur-fitur yang dimiliki digital library ini memudahkan pengguna untuk dapat mengakses jurnal terbaru dan memudah pengguna untuk menyortir jurnal dengan keyword tertentu. 
Semua sumber literatur yang didapatkan dicari berdasarkan judul, keyword dan abstract. Kemudian akan disaring berdasarkan kriteria inkulisi dan eksklusinya. Kriteria inklusi difokuskan pada:

- Literatur berupa jurnal, konferens, workshop dan buku.

- Batas waktu publikasi dari tahun 2010 sampai 2019.

- Literatur yang didapatkan merupakan literatur berbahasa inggris.

- Literatur yang membahas ekosistem OSS

- Literatur yang membahas evolusi ekosistem OSS

Sedangkan kriteria ekslusinya :

- Literatur yang bentuk editorial, dan resume.

- Literatur yang tidak berhubungan dengan OSS ekosistem,

- Literatur yang tidak relevan dengan topik paper

- Literatur yang dipublikasi sebelum tahun 2010

Berikut semua keyword pencarian yang digunakan :

1. Software Ecosystem

2. Open Source Software Ecosystem

3. Open Source Ecosystem

4. Evolution of Open Source Software Ecosystem

Pada tahap pencarian literatur menggunakan keyword diatas ada beberapa pengecualian yang kami lakukan pada sumber yang ada pada sciencedirect dimana kami menggunakan kutip dua untuk memperkecil pencarian. Keyword yang kami gunakan pada sciencedirect menjadi "Software Ecosystem", "Open Source Software Ecosystem", "Open Source Ecosystem", dan "Evolution of Open Source Software Ecosystem". Penggunaan kutip dua, untuk menghindari hasil pencarian yang tidak sesuai dengan keyword, karna akan sulit untuk menyaring hasil pencariannya bahkan banyak hasil pencarian yang judulnya sangat jauh berbeda dari topik yang sesuai. Sedangkan pencarian pada IEEE dilakukan berbeda karena hasil pencarian dengan menggunakan kutip dan tidak menggunakan kutip hasilnya tidak terlalu jauh berbeda.

\subsection{Study Selection}

Pada saat proses pencarian awal dengan menggunakan keyword dan berdasarkan tahun publikasi yakni 2010-2019, jumlah literatur yang didapat adalah sebanyak 1099 literatur. Total 1099 judul literatur tersebut akan disaring kembali dan kemudian diidentifikasi berdasarkan kriteria inklusi dan ekslusi. Pada proses penyaringan dengan kriteria inklusi didapatkan 52 literatur, kemudian 52 literatur ini dipisah untuk dianalisa kembali berdasarkan kriteria ekslusi, relevan topik dan judul. Pada hasil analisa ini didapat 44 literatur yang sesuai berdasarkan kriteria eksklusi, relevan topik dan judul, setelah mendapatkan 44 literatur tersebut dilakukan tahap penyaringan kembali dengan membaca satu persatu setiap bagian pada 44 literatur yang meliputi abstrak, keyword dan kesimpulan. Dari tahap tersebut dihasil kan 31 literatur yang terkumpul yang dinilai sesuai dan dijadikan sebagai bahan studi literatur. 


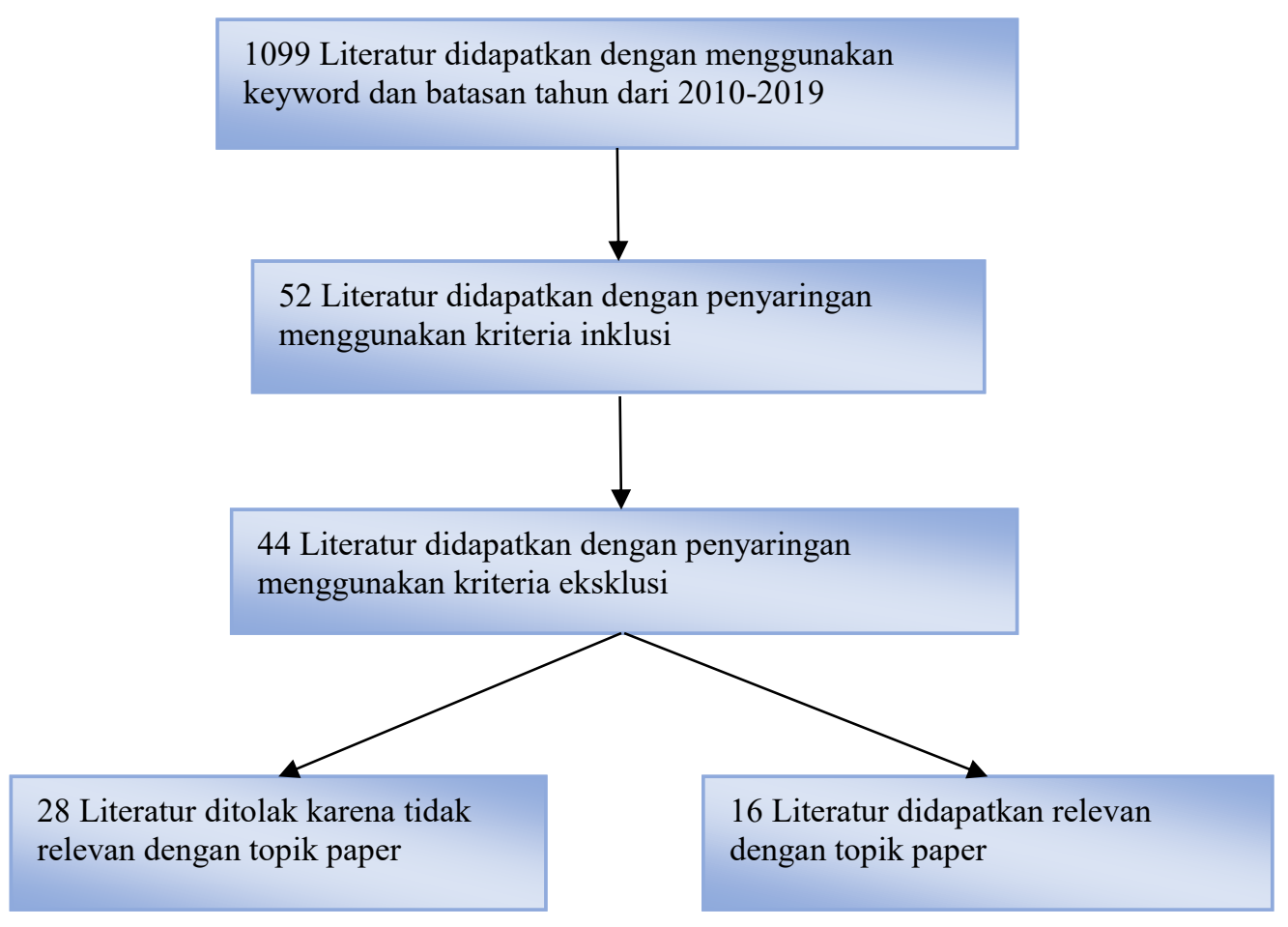

Gambar 1. Seleksi Inklusi dan Ekslusi pada Hasil Pencarian Literatur

\subsection{Quality Assesment}

Untuk memperoleh hasil penelitian yang berkualitas mengenai Systematic Literature Review mengenai aspek-aspek dalam open source software ecosystem, ada beberapa kriteria penilaian yang digunakan:

1. Apakah sumber dari data memiliki standar yang baik?

2. Apakah sumber data relevan dengan topik paper?

3. Apakah sumber data dapat mengcover semua tujuan studi?

Setiap pertanyaan diatas akan diajawab dengan jawaban "Yes" atau "No" atau "Partial". Dengan nilai skor jawaban Yes $=1, N o=0$, Partial $=0,5$, penilaian ini berdasarkan Kitchenham [5]. Reviewer akan memberikan skor untuk memvalidasi hasilnya.

\subsection{Proses Ekstraksi Data dan Sintesis}

Hasil pencarian data menghasilkan 16 literatur yang relevan dengan topik paper. Dari hasil yang didapatkan akan di susun dalam bentuk spreadsheet yang terdapat dalam tabel 1. Dalam proses sintesis data, kami membaca dan menganalisis data ekstraksi untuk melihat bagaimana hasil ekstaraksinya bisa dibandingkan. Hasil sintesis akan dijelaskan pada tahap selanjutnya. 


\section{Hasil Ekstraksi Data}

Hasil pencarian data didapatkan sebanyak 16 literatur utama yang relevan dan telah di ekstraksi sesuai dengan kriteria inklusi dan eksklusi ditunjukkan pada Tabel 1 dari sumber dari IEEE dan Tabel 2 dari sumber Sciencedirect. Pada setiap review akan diidentifikasi sebagai berikut :

- Fokus tinjauan artikel terdiri dari Research Question (RQ), Software Engineering Topic (SERT) atau Undertake Research (RT).

- Skor kualitas dinilai berdasarkan jawaban dari pertanyaan yang terdapat pada Quality Assesment.

Tabel 1. Hasil Ekstraksi Data dari Sumber IEEE

\begin{tabular}{|c|c|c|c|c|c|c|}
\hline $\begin{array}{l}\text { Study } \\
\text { Ref. }\end{array}$ & $\begin{array}{c}\text { Fokus } \\
\text { Review }\end{array}$ & Tahun & $\begin{array}{l}\text { Tipe } \\
\text { Paper }\end{array}$ & $\begin{array}{l}\text { Banyak } \\
\text { Studi } \\
\text { Utama }\end{array}$ & $\begin{array}{l}\text { Quality } \\
\text { Total } \\
\text { Score }\end{array}$ & $\begin{array}{l}\text { Judul } \\
\text { Artikel }\end{array}$ \\
\hline [6] & RQ & 2014 & Conference & 15 & 2,5 & $\begin{array}{l}\text { Understanding the evolution of } \\
\text { socio-technical aspects in open } \\
\text { source ecosystems }\end{array}$ \\
\hline [7] & RQ & 2011 & Conference & 14 & 3 & $\begin{array}{l}\text { Analysing the evolution of social } \\
\text { aspects of open source software } \\
\text { ecosystems }\end{array}$ \\
\hline [4] & RQ & 2013 & Conference & 38 & 3 & $\begin{array}{l}\text { Evolusi dari ekosistem software } R \\
\text { The Evolution of the R Software } \\
\text { Ecosystem }\end{array}$ \\
\hline [1] & RQ & 2013 & Conference & 26 & 3 & $\begin{array}{l}\text { Aspek inter-dependencies dalam } \\
\text { ekosistem OSS : studi kasus } \\
\text { ekosistem Apache }\end{array}$ \\
\hline [2] & RT & 2013 & Conference & 16 & 2 & $\begin{array}{l}\text { Aspek Sosial Point of view dalam } \\
\text { hal kontribusi pada kasus } \\
\text { GNOME Ekosistem }\end{array}$ \\
\hline [8] & RQ & 2011 & Conference & 23 & 2 & $\begin{array}{l}\text { Joining Free/Open Source } \\
\text { Software Communities: } \\
\text { An Analysis of Newbies' First } \\
\text { Interactions on Project Mailing } \\
\text { Lists }\end{array}$ \\
\hline [9] & RT & 214 & Conference & 8 & 3 & $\begin{array}{l}\text { Risk Based Testing of } \\
\text { Open Source Software (OSS) }\end{array}$ \\
\hline [10] & RQ & 2015 & Conference & 30 & 2.5 & $\begin{array}{l}\text { Identifying Similarity of Software } \\
\text { in Apache Ecosystem - An } \\
\text { Exploratory Study }\end{array}$ \\
\hline [11] & RQ & 2018 & Conference & 25 & 1 & $\begin{array}{l}\text { CrossSim: exploiting mutual } \\
\text { relationships to detect } \\
\text { similar OSS projects }\end{array}$ \\
\hline$[12]$ & RT & 2019 & Conference & 47 & 1.5 & $\begin{array}{l}\text { The Dynamics of Openness and } \\
\text { the Role of User } \\
\text { Communities: A Case Study in the } \\
\text { Ecosystem of } \\
\text { Open Source Gaming Handhelds }\end{array}$ \\
\hline
\end{tabular}


Tabel 2. Hasil Ekstraksi Data dari Sumber Sciencedirect

\begin{tabular}{|c|c|c|c|c|c|c|}
\hline $\begin{array}{l}\text { Study } \\
\text { Ref. }\end{array}$ & $\begin{array}{l}\text { Fokus } \\
\text { Review }\end{array}$ & Tahun & $\begin{array}{l}\text { Tipe } \\
\text { Paper }\end{array}$ & $\begin{array}{c}\text { Banyak } \\
\text { Studi } \\
\text { Utama }\end{array}$ & $\begin{array}{l}\text { Quality } \\
\text { Total } \\
\text { Score }\end{array}$ & $\begin{array}{c}\text { Judul } \\
\text { Artikel }\end{array}$ \\
\hline [13] & RQ & 2013 & Jurnal & 99 & 2 & $\begin{array}{l}\text { Software ecosystems }-A \\
\text { systematic literature review }\end{array}$ \\
\hline$[14]$ & RT & 2013 & Jurnal & 83 & 2 & $\begin{array}{l}\text { The attraction of contributors in } \\
\text { free and open source software } \\
\text { projects }\end{array}$ \\
\hline$[15]$ & RQ & 2014 & Jurnal & 48 & 2 & $\begin{array}{l}\text { Bridges and barriers to hardware- } \\
\text { dependent software ecosystem } \\
\text { participation - a case study }\end{array}$ \\
\hline$[16]$ & RQ & 2017 & Jurnal & 65 & 2 & $\begin{array}{l}\text { Motivating the Contributions: An } \\
\text { Open Innovation Perspective on } \\
\text { What to Share as Open Source } \\
\text { Software }\end{array}$ \\
\hline [17] & RQ & 2017 & Jurnal & 89 & 3 & $\begin{array}{l}\text { Open Source Software } \\
\text { Ecosystems: A Systematic } \\
\text { Mapping }\end{array}$ \\
\hline$[18]$ & RQ & 2019 & Jurnal & 48 & 3 & $\begin{array}{l}\text { Reference Coupling: An } \\
\text { exploration of inter-project } \\
\text { technical dependencies and their } \\
\text { characteristics within large } \\
\text { software ecosystems }\end{array}$ \\
\hline
\end{tabular}

\section{Diskusi Research Question}

Sebanyak 16 literatur dibagi berdasarkan topik untuk memudahkan dalam identifikasi dan mapping. Hal ini dilakukan untuk mempermudah untuk melihat keterkaitan antar literatur. Proses identifikasi dilakukan untuk dapat menjawab RQ yang sebelumnya telah dijabarkan. Berikut jawaban dari RQ penelitian ini dengan tujuan untuk mencari pengaruh aspek ekosistem OSS pada evolusi software.

RQ1 : Aspek-aspek apa saja yang ada pada ekosistem OSS?

Terdapat tiga aspek Ekosistem OSS yang dibahas pada penelitian ini yaitu aspek sosial, contributions, dan dependencies. Aspek sosial pada ekosistem OSS adalah dampak yang dimiliki pengguna dan komunitas pengembang (dan interaksinya) terhadap evolusi proyek perangkat lunak [17]. Variabilitas sosial merupakan salah satu faktor yang dapat membawa stabilitas lebih dan mungkin berkontribusi pada ekosistem yang lebih sehat [13].

Aspek Contributions adalah bagaimana melihat peran dan partisipasi setiap anggota suatu proyek OSS berpengaruh pada perkembangan ekosistem. Kontributor mendapatkan manfaat pribadi dari pengembangan aset bersama yang dimana tidak tersedia untuk pengguna gratis yang hanya menggunakan aset [17].

Aspek Dependencies merupakan saling ketergantungan kerja di antara anggota ekosistem. Ini adalah hubungan simbiosis antara aktor ekosistem [17]. Dependencies pada proyek-proyek lain dalam suatu ekosistem lebih mungkin untuk menarik perhatian. Pendatang baru mungkin 
memutuskan untuk bergabung dengan proyek berdasarkan pengetahuan yang lebih dalam tentang struktur sistem serta ketergantungan eksternal. Selain itu informasi tentang ekosistem perangkat lunak dan dependensi teknis di dalamnya memungkinkan eksplorasi lebih lanjut dan pemodelan ekosistem perangkat lunak, suatu area yang saat ini kurang dipahami dalam literatur rekayasa perangkat lunak [18].

RQ2: Bagaimana pengaruh aspek-aspek tersebut terhadap evolusi ekosistem OSS ?

\section{- Sosial}

Studi yang berkaitan dengan aspek sebelumnya telah dilakukan oleh Goeminne, dalam paper tersebut menyatakan bahwa aspek sosial memiliki dampak yang signifikan terhadap perkembangan ekosistem dari waktu ke waktu [6][3] dimana komunikasi sebagai wadah sosial membuka interaksi perusahaan dengan komunitas pengguna [9], [12]. Ekosistem harus fokus pada bagaimana mengatur komunikasi dan hubungan yang baik dengan pengguna sebagai salah satu faktor dominan untuk partisipasi ekosistem [15] yang mengarah ke intensitas kontribusi.

Penelitian terhadap sosial aspek juga telah dilakukan pada studi kasus ekosistem eclipse [19]. Penelitian ini memberikan informasi mengenai implikasi tentang kasus dimana vendor mendesain ekosistemnya secara strategis dan juga kasus dimana pengguna dapat berpartisipasi dalam ekosistem yang sudah ada [16], [19].

\section{- Contributions}

Dalam faktor Core dan user-contribution ini kami mereview evolusi dari salah satu ekosistem OSS yaitu ekosistem R Software. Dalam studi empiris yang dilakukan German et al. [4] aspek contribution akan dilihat berdasarkan Core dan User-Contributions paket.

- Karakteristik kode dari paket Core dan User-Contributed

- Paket terdiri dari banyak tipe file yang berbeda-beda

- Paket didokumentasikan secara luas, dengan Core paket yang lebih banyak dari UserContributed paket.

- Kode User-contributed paket lebih sedikit dibanding Core paket

- Banyak paket yang utamanya diimplementasikan pada R kemudian diikuti oleh C.

- Perkembangan paket Core dan User-Contributed

- Pertumbuhan user-contributed yang sangat cepat,

- Semakin sedikit Core paket maka semakin sedikit juga paket yang rilis.

- Ukuran dari rata-rata paket tetap stabil.

- Recommended paket adalah paket lama, dengan paket yang populer adalah paket lama dari Contributed paket; kebanyakan paket dirawat dengan sangat baik.

- Ketergantungan antar paket Core dan User-Contributed

- Mailing list didominasi oleh kontribusi paket yang populer.

- Komunitas pengguna mengalami pertumbuhan, sedangkan komunitas pengembang mengalami stagnan.

- Kontributor baru atau yang awam dan kontributor ahli terlibat dalam banyak proyek yang berbeda yang lebih sering terlibat dalam aktivitas lokalisasi, sedangkan 
kontributor umumnya lebih sering terlibat dalam coding Kegiatan di sejumlah proyek [6].

- Kami mengamati bahwa kontributor cenderung membatasi diri untuk sejumlah jenis kegiatan, tetapi semakin aktif kontributor, semakin besar keinginannya untuk berkontribusi pada tipe proyek yang berbeda. Ketika mempelajari evolusi Gnome kontributor, kami mengamati kecenderungan spesialisasi terhadap jenis kegiatan yang lebih sedikit. Kami juga mengamati bahwa, selama tahun-tahun terakhir, upaya atau keinginan untuk kontribusi di masing-masing jenis kegiatan belajar semakin menurun [2], [6].

- Karena perangkat lunak open source sudah tidak perlu dikembangkan dari perusahaan awal, sulit untuk menghilangkan kemungkinan bahwa pengembang yang tidak diketahui telah disalin dan disisipkan code yang diragukan keasliannya.

Dapat dilihat bahwa minoritas kontributor proyek lebih memiliki kerja yang lebih besar dibanding kontributor mayoritas. Sebesar $80 \%$ proyek diselesaikan oleh hanya sedikit kontributor. Jumlah kontributor aktif adalah salah satu indikator terpenting dari kesehatan dan kualitas ekosistem OSS [17]. Kontributor baru atau yang awam dan kontributor ahli terlibat dalam banyak proyek yang berbeda yang lebih sering terlibat dalam aktivitas lokal, sedangkan kontributor umumnya lebih sering terlibat dalam coding kegiatan di sejumlah proyek. Kami mengamati bahwa kontributor cenderung membatasi diri untuk sejumlah jenis kegiatan, tetapi semakin aktif kontributor, semakin besar keinginannya untuk berkontribusi pada tipe proyek yang berbeda. Ketika mempelajari evolusi Gnome kontributor, kecenderungan spesialisasi terhadap jenis kegiatan yang lebih sedikit. Selama beberapa tahun terakhir, upaya atau keinginan untuk kontribusi di masing-masing jenis kegiatan belajar semakin menurun [6].

Kontribusi sangat mempengaruhi evolusi Ekosistem OSS karena gelombang masuk yang berkelanjutan dari orang-orang yang mau berkontribusi sangat penting untuk keberlanjutan proyek [8]. Membuat pengguna tertarik berkontribusi merupakan salah satu cara untuk meningkatkan ekosistem OSS. Menurut [14] proyek yang menarik cenderung menjadi pendorong yang kuat untuk menarik perhatian kontributor.

\section{- Dependencies}

Jika melihat dependency dari suatu proyek terhadap proyek yang terbaru secara keseluruhan, dapat diyatakan bahwa proyek klien cenderung memperbaharui dependency mereka ketika perubahan besar terjadi dalam proyek yang mereka gantungkan dirilis, termasuk aktifitas bugfixing. Dampak dari proyek klien terhadap upgrade proyek yang digantungkan proporsinya sangat kecil yaitu sekitar $5 \%$ dipengaruhi oleh perubahan dalam proyek yang mereka gantungkan. Namun, ada dependensi tertentu seperti frameworks atau library yang menawarkan layanan lintas sektor yang sangat luas,yang bisa mempengaruhi kode sumber proyek klien saat proyek yang digantungkan diperbaharui.

Ekosistem yang sangat besar berisi ribuan proyek yang saling berhubungan dan berkembang dengan cepat di mana proyek-proyek klien secara bergantung bergantung pada proyek library. Contoh ekosistem tersebut di industri termasuk yang ada di Facebook, Google, dan Microsoft, di mana banyak proyek perangkat lunak biasanya berada di repositori monolitik dan klien dibangun dan diuji terhadap versi library terbaru setiap kali library berubah [11]. Hal ini memungkinkan ada munculnya proyek yang mirip satu dengan yang lainnya. Ada beberapa proyek dengan sedikit dependecies; misalnya, tiga proyek milik kategori L memiliki $100 \%$ 
kesamaan. Nilai kesamaan yang rendah di antara proyek-proyek disebabkan oleh kuantitas ketergantungan yang tinggi yang digunakan oleh masing-masing proyek. [10].

Dalam menganalisis evolusi dari ekosistem OSS berdasarkan faktor dependencies kami mereview salah satu ekosistem OSS yaitu ekosistem Apache. Berdasarkan penelitian sebelumnya yang bersumber dari [1] telah dilakukan penelitian terhadap pengaruh dependencies pada ekosistem software. Penelitian dilakukan dengan mengobservasi 147 project yang ada dalam periode 14 tahun dan menghasilkan 1,964 rilis. Kemudian projek-projek tersebut akan diekstrak dan kemudian dicari dependency yang ada diantara projek-projek tersebut.

Menurut Bavota et al. [1] ekosistem Apache terus meningkat secara linear dari tahun ke tahun. Semakin meningkatnya ekosistem Apache maka semakin meningkat pula dependency antara projeknya. Dapat disimpulkan bahwa dependency antara proyek semakin meningkat seiring dengan berjalannya evolusi.

\section{Kesimpulan}

Dalam penelitian ini kami menganalisa aspek-aspek yang mempengaruhi ekosistem OSS pada evolusi OSS. Dari beberapa aspek yang telah kami bahas diatas dapat disimpulkan:

1. Aspek sosial memiliki dampak yang signifikan terhadap evolusi ekosistem, dimana komunikasi antar komunitas dalam sebuah ekosistem OSS mempengaruhi contributions dan dependencies yang merupakan pendorong sebuah ekosistem dapat berkembang dan berevolusi.

2. Dalam hal aspek Contribution semakin banyak paket Core yang dirilis maka semakin banyak pula contribution dari pengguna, maka dapat disimpulkan semakin meningkatnya evolusi ekosistem maka semakin tinggi pula contribution usernya, begitu pula sebaliknya. Namun selain itu terdapat beberapa faktor yang juga mempengarui kontribusi yaitu daya tarik proyek dan keaktifan komunitas dalam merespon pengguna.

3. Semakin meningkatnya suatu ekosistem maka semakin meningkat pula dependency antara projeknya. Dapat disimpulkan bahwa dependency antara proyek semakin meningkat seiring dengan berjalannya evolusi.

Penelitian masih memiliki banyak batasan karena sumber data literatur yang hanya berasal dari Sciencedirect dan IEEE. Kedepannya diharapkan cakupan sumber data dapat semakin luas sehingga pemahaman tentang evolusi ekosistem OSS menjadi lebih detail dari sebelumnya.

\section{DAFTAR REFERENSI}

[1] G. Bavota, G. Canfora, M. D. Penta, R. Oliveto, and S. Panichella, "The Evolution of Project Inter-dependencies in a Software Ecosystem: The Case of Apache," in 2013 IEEE

International Conference on Software Maintenance, (2013), pp. 280-289.

[2] M. Goeminne, M. Claes, and T. Mens, "A historical dataset for the GNOME ecosystem," in Proceedings of the 10th Working Conference on Mining Software Repositories, (2013), pp. 225-228.

[3] T. Kilamo, I. Hammouda, T. Mikkonen, and T. Aaltonen, "From proprietary to open sourceGrowing an open source ecosystem," J. Syst. Softw., vol. 85, no. 7, pp. 1467-1478, Jul. (2012).

[4] D. M. German, B. Adams, and A. E. Hassan, "The Evolution of the R Software Ecosystem," in 2013 17th European Conference on Software Maintenance and Reengineering, (2013), pp. 243-252.

[5] B. Kitchenham et al., "Systematic literature reviews in software engineering-a tertiary study," Inf. Softw. Technol., vol. 52, no. 8, pp. 792-805, (2010). 
[6] M. Goeminne, "Understanding the evolution of socio-technical aspects in open source ecosystems," in 2014 Software Evolution Week-IEEE Conference on Software Maintenance, Reengineering, and Reverse Engineering (CSMR-WCRE), (2014), pp. 473-476.

[7] T. Mens and M. Goeminne, "Analysing the evolution of social aspects of open source software ecosystems.," in IWSECO@ICSOB, (2011),pp. 1-14.

[8] C. Jensen, S. King, and V. Kuechler, "Joining Free/Open Source Software Communities: An Analysis of Newbies' First Interactions on Project Mailing Lists," in 2011 44th Hawaii International Conference on System Sciences, (2011), pp. 1-10.

[9] I. Yahav, R. S. Kenett, and X. Bai, "Risk Based Testing of Open Source Software (OSS)," in 2014 IEEE 38th International Computer Software and Applications Conference Workshops, (2014), pp. 638-643.

[10]L. Hernández and H. Costa, "Identifying Similarity of Software in Apache Ecosystem - An Exploratory Study," in 2015 12th International Conference on Information Technology - New Generations, (2015), pp. 397-402.

[11]P. T. Nguyen, J. D. Rocco, R. Rubei, and D. D. Ruscio, "CrossSim: Exploiting Mutual Relationships to Detect Similar OSS Projects," in 2018 44th Euromicro Conference on Software Engineering and Advanced Applications (SEAA), (2018), pp. 388-395.

[12]M. A. Zaggl, T. G. Schweisfurth, and C. Herstatt, "The Dynamics of Openness and the Role of User Communities: A Case Study in the Ecosystem of Open Source Gaming Handhelds," IEEE Trans. Eng. Manag., pp. 1-12, (2019).

[13]K. Manikas and K. M. Hansen, "Software ecosystems-A systematic literature review," J. Syst. Softw., vol. 86, no. 5, pp. 1294-1306, (2013).

[14]C. Santos, G. Kuk, F. Kon, and J. Pearson, "The attraction of contributors in free and open source software projects," J. Strateg. Inf. Syst., vol. 22, no. 1, pp. 26-45, Mar. (2013).

[15]K. Wnuk, P. Runeson, M. Lantz, and O. Weijden, "Bridges and barriers to hardwaredependent software ecosystem participation - A case study," Inf. Softw. Technol., vol. 56, no. 11, pp. 1493-1507, Nov. (2014).

[16]J. Linåker, H. Munir, K. Wnuk, and C. E. Mols, "Motivating the contributions: An Open Innovation perspective on what to share as Open Source Software," J. Syst. Softw., vol. 135, pp. 17-36, Jan. (2018).

[17]O. Franco-Bedoya, D. Ameller, D. Costal, and X. Franch, "Open source software ecosystems: A Systematic mapping," Inf. Softw. Technol., vol. 91, pp. 160-185, (2017).

[18]K. Blincoe, F. Harrison, N. Kaur, and D. Damian, "Reference Coupling: An Exploration of Inter-project Technical Dependencies and their Characteristics within Large Software Ecosystems," Inf. Softw. Technol., (2019).

[19]K. Mizushima and Y. Ikawa, "A structure of co-creation in an open source software ecosystem: A case study of the eclipse community," in 2011 Proceedings of PICMET '11: Technology Management in the Energy Smart World (PICMET), (2011), pp. 1-8. 